\title{
Model matematis predator-prey tanaman padi, hama penggerek batang, tikus, dan wereng batang coklat di Karawang
}

\author{
Tesa Nur Padilah *, Betha Nurina Sari, H. Hannie \\ Fakultas Ilmu Komputer, Universitas Singaperbangsa Karawang. Jalan H.S. Ronggowaluyo, \\ Telukjambe Timur, Karawang 41361, Jawa Barat, Indonesia \\ * Corresponding Author. E-mail: tesa.nurpadilah@staff.unsika.ac.id \\ Received: 15 November 2017; Revised: 17 September 2018; Accepted: 21 September 2018
}

\begin{abstract}
Abstrak
Karawang merupakan salah satu pusat penanaman padi di Pulau Jawa. Keberhasilan panen dapat terganggu oleh adanya organisme pengganggu tumbuhan (OPT) sehingga dapat mengancam target swasembada beras. Hubungan antara tanaman padi dengan OPT dapat dibentuk menjadi suatu model matematis yaitu model predator-prey. Untuk itu, penelitian ini bertujuan untuk menganalisis model matematis predator-prey tanaman padi dan OPT. Predator (pemangsa) adalah makhluk hidup yang memakan mangsa (prey). Model predator-prey antara tanaman padi dengan OPT yang dibahas adalah model tiga predator yaitu hama penggerek batang, tikus, dan wereng batang coklat dengan prey yaitu padi. Pertumbuhan padi mengikuti model pertumbuhan logistik. Model yang diturunkan berbentuk sistem persamaan diferensial nonlinier. Pada model diperoleh lima titik ekuilibrium. Analisis perilaku model dilakukan pada tiga titik ekuilibrium dan ketiganya bersifat stabil asimtotik. Simulasi model dengan menggunakan software Maple 13 sejalan dengan analisis perilaku model. Faktor-faktor yang berpengaruh agar populasi hama penggerek batang, tikus, dan wereng batang coklat dapat menurun bahkan hilang dari populasi yaitu tingkat kematian alami serta tingkat interaksi padi terhadap hamahama tersebut.
\end{abstract}

Kata Kunci: model pertumbuhan logistik, model predator-prey, OPT, titik ekuilibrium

\section{Predator-prey mathematical model of rice plants, stem borer, rat, and brown planthopper in Karawang}

\begin{abstract}
Karawang was one of the center of rice planting in Java Island. The success of the harvest may be disrupted by the presence of plant pest organisms that may threaten the rice self-sufficiency target. The relationship between rice plants and pests can be formed into a mathematical model, that was a predator-prey model. Therefore, this research aimed to analyze the mathematical model of predatorprey between rice plants and plant pest organisme. Predators were living things that eat prey. The predator-prey model between rice plants and pests discussed was a three predator model of stem borer, rat, and brown stem rhizome with the prey, that was rice. Rice growth follows the logistic growth model. The derived model was an nonlinear differential equation system. In this model obtained five equilibrium points. Model behavioral analysis was performed on three equilibrium points and they were stable asymptotically. Simulations of the model using Maple 13 software were in good agreement with behavioral analysis model. Factors that influence the stem borer, rat, and brown planthopper population could decrease even disapear from the population were the natural death rate and the interaction rate of rice to the pests.
\end{abstract}

Keywords: logistic growth model, predator-prey model, plant pest organisms, equilibrium point

How to Cite: Padilah, T., Sari, B., \& Hannie, H. (2018). Model predator-prey padi, hama penggerek batang, tikus, dan wereng batang coklat di Karawang. Pythagoras: Jurnal Pendidikan Matematika, 13(1), 52-62. doi:http://dx.doi.org/10.21831/pg.v13i1.16880

doi http://dx.doi.org/10.21831/pg.v13i1.16880 


\section{PENDAHULUAN}

Kabupaten Karawang mempunyai potensi besar dalam subsektor pertanian khususnya tanaman pangan baik ditinjau dari aspek sumber daya alam maupun sumber daya manusia. Sumber daya petani sangat menunjang keberhasilan pembangunan pertanian di Kabupaten Karawang, Provinsi Jawa Barat, Indonesia dimana 61,9\% penduduk bergerak di bidang usaha pertanian dengan persentase buruh tani sekitar 59,43\% (DPKPP Kabupaten Karawang, 2014). Selain itu, Karawang merupakan salah satu pusat penanaman padi di Pulau Jawa (Makarim \& Suhartatik, 2009). Sebagai pusat penanaman padi, sudah seharusnya hasil panen padi dari tahun ke tahun mengalami peningkatan. Akan tetapi, keberhasilan panen dapat terganggu oleh adanya organisme pengganggu tumbuhan (OPT) sehingga dapat mengancam target swasembada beras. Tingginya serangan OPT di Kabupaten Karawang pada tahun 2013 berturut-turut adalah penggerek batang padi, tikus, wereng batang coklat, $\mathrm{BCB}$, hama putih palsu, dan siput murbei (DPKPP Kabupaten Karawang, 2013).

Hubungan antara tanaman padi dengan OPT dapat dibentuk menjadi suatu model matematis yaitu model predator-prey. Predator (pemangsa) adalah makhluk hidup yang memakan mangsa (prey). Model predator-prey yang paling sederhana diperkenalkan oleh A. J. Lotka pada tahun 1925 dan V. Volterra pada tahun 1926. Model tersebut dikenal dengan istilah Model Lotka-Volterra. Model Lotka-Volterra adalah model populer yang menggambarkan interaksi predator dan prey atau interaksi kompetitif antara dua spesies (Haberman, 1998). Model LotkaVolterra hanya melibatkan satu predator dan satu prey, akan tetapi model tersebut dapat dikembangkan menjadi model dengan satu prey dan beberapa predator. Korobeinikov dan Wake telah melakukan penurunan model untuk dua predator dan satu prey (Korobeinikov \& Wake, 1999). Pada model ini, asumsi pertumbuhan prey mengikuti model Malthus. Model pertumbuhan Malthus dianggap kurang realistis karena pada kenyataannya, suatu populasi tidak dapat bertambah secara terus menerus sebagai akibat adanya keterbatasan makanan serta munculnya predator. Oleh karena itu, pada tahun 1838, Verhulst memperkenalkan model pertumbuhan logistik. Model ini menggunakan kaidah logistik yaitu persediaan logistik ada batasnya. Model ini juga mengasumsikan bahwa pada masa tertentu jumlah populasi akan mendekati nilai daya dukung lingkungan.
Pada model pertumbuhan Malthus, laju pertumbuhan diasumsikan sebagai konstanta. Akan tetapi, pada model pertumbuhan logistik, laju pertumbuhan diasumsikan sebagai fungsi populasi (Edwards \& Penney, 2008). Selanjutnya, Nugroho dan Reorita mengkaji model dua predator dan satu prey dengan pertumbuhan prey mengikuti pertumbuhan logistik agar lebih realistik (Nugroho \& Reorita, 2013).

Terkait dengan analisis model predatorprey beberapa penelitian telah dilakukan. Misalnya, Wijayanti \& Kharis (2015) yang meneliti tentang analisis model predator-prey dua spesies dengan fungsi respon Holling tipe III, dimana dari penelitian tersebut diperoleh hasil bahwa secara analitik terdapat tiga titik keseimbangan dengan beberapa syarat batas dalam sistem tersebut, sehingga terdapat enam kondisi titik keseimbangan, dimana tiga titik keseimbangan bersifat stabil dan tiga kondisi titik lainnya bersifat tidak stabil.

Pada penelitian ini, model predator-prey antara tanaman padi dengan OPT yang dibahas adalah model tiga predator yaitu hama penggerek batang, tikus, dan wereng batang coklat dengan prey yaitu padi. Pertumbuhan padi mengikuti model pertumbuhan logistik. Model yang diturunkan berbentuk sistem persamaan diferensial nonlinier. Pada model yang telah diturunkan tersebut, dicari titik ekuilibrium kemudian dilakukan analisis kestabilan titik ekuilibrium untuk mengetahui perilaku penyelesaian sistem untuk jangka waktu tertentu. Berdasarkan analisis perilaku model, dapat ditentukan faktor-faktor yang berpengaruh agar populasi ketiga hama dapat menurun bahkan hilang dari populasi. Selanjutnya dilakukan simulasi model dengan software Maple 13 untuk mengetahui apakah analisis perilaku model sesuai dengan simulasi model.

Berdasarkan uraian yang telah dikemukakan tersebut maka penelitian ini bertujuan untuk penelitian ini bertujuan untuk menganalisis model matematis predator-prey tanaman padi dan organisme pengganggu tumbuhan (OPT).

\section{METODE}

Penelitian ini berupa analisis kualitatif yang terdiri dari beberapa tahapan sebagai berikut: (1) penentuan asumsi model, dimana tahapan ini adalah tahap menentukan asumsi model (Nugroho \& Reorita, 2013). Asumsi diperlukan sebagai batasan sejauh mana model akan dibuat; (2) penentuan parameter dan variabel, dimana tahapan ini dilakukan untuk menentukan parameter dan variabel apa saja yang sesuai dengan 
model; (3) penurunan model, dimana penurunan model merupakan langkah penyajian hubungan antara predator dan prey ke dalam model matematika yang berbentuk sistem persamaan diferensial; (4) penentuan titik ekuilibrium, dimana tahap ini merupakan lanjutan setelah penurunan model adalah menentukan titik ekuilibrium; (5) analisis perilaku model, dimana analisis perilaku model dilakukan dengan terlebih dahulu melinierisasi sistem di sekitar titik ekuilibrium (Machowski, Bialek, \& Bumby, 2011), dan selanjutnya untuk mengetahui kestabilan titik ekuilibrium tersebut, dilakukan analisis terhadap bagian riil nilai eigen dari persamaan karakteristik (Edwards \& Penney, 2008). Penentuan bagian riil nilai eigen menggunakan kriteria Routh-Hurwitz (Olsder, Woude, Maks, \& Jeltsema, 2011); (6) simulasi model, dimana simulasi model dilakukan menggunakan software Maple 13. Simulasi ini dilakukan untuk mengetahui apakah analisis perilaku model sesuai dengan simulasi model. Berdasarkan simulasi, dapat diketahui faktor-faktor yang berpengaruh agar populasi hama penggerek batang, tikus, dan wereng batang coklat dapat menurun bahkan hilang dari populasi; dan (7) penarikan kesimpulan, dimana tahap terakhir yang dilakukan pada penelitian ini adalah penarikan kesimpulan.

\section{HASIL DAN PEMBAHASAN}

Kelompok individu pada model predatorprey antara padi, hama penggerek batang, tikus,

Tabel 1. Daftar Variabel

\begin{tabular}{cl} 
Simbol & \multicolumn{1}{c}{ Definisi } \\
$\boldsymbol{P}$ & jumlah padi (prey) \\
$\boldsymbol{B}$ & jumlah penggerek batang \\
$\boldsymbol{T}$ & jumlah tikus \\
$\boldsymbol{W}$ & jumlah wereng batang coklat
\end{tabular}

Tabel 2. Daftar Parameter dan wereng batang coklat dibagi menjadi empat kelompok yaitu subpopulasi padi $(P)$, penggerek batang $(B)$, tikus $(T)$, dan wereng batang coklat $(W)$. Asumsi-asumsi yang digunakan pada model ini adalah sebagai berikut: (10 populasi predator dan prey bersifat tertutup, ini berarti tidak ada predator dan prey yang melakukan migrasi; (2) model populasi predator-prey yang dikaji terdiri dari tiga predator dan satu prey. Prey yaitu tanaman padi, sedangkan predator yaitu hama penggerek batang, tikus, dan wereng batang coklat; (3) apabila tidak ada interaksi antara predator dan prey maka pertumbuhan prey mengikuti model logistik dan penurunan predator mengikuti model Malthus; (4) tidak terjadi interaksi dan kompetisi antar ketiga predator; (5) tidak ada penyakit pada predator dan prey; (6) daya dukung lingkungan prey bernilai konstan; (7) simulasi model dilakukan menggunakan software Maple 13.

Variabel-variabel yang digunakan bernilai nonnegatif, sedangkan parameter-parameternya bernilai positif, yang disajikan dalam Tabel 1 dan Tabel 2.

Berdasarkan variabel dan parameter yang telah ditentukan pada Tabel 1 dan Tabel 2, selanjutnya pemodelan dilakukan dengan memperhatikan faktor-faktor yang mempengaruhi perubahan jumlah setiap kelompok pada populasi.

\section{efinisi}

\begin{tabular}{cl} 
Simbol & \multicolumn{1}{c}{ Definisi } \\
$\boldsymbol{K}$ & daya dukung lingkungan untuk padi (prey) \\
$r$ & tingkat pertumbuhan intrinsik padi (prey) \\
$\alpha$ & tingkat interaksi penggerek batang terhadap padi \\
$\beta$ & tingkat interaksi tikus terhadap padi \\
$\theta$ & tingkat interaksi wereng batang coklat terhadap padi \\
$\boldsymbol{c}$ & tingkat kematian alami penggerek batang \\
$\boldsymbol{b}$ & tingkat kematian alami tikus \\
$\boldsymbol{m}$ & tingkat kematian alami wereng batang coklat \\
$\gamma$ & tingkat interaksi padi terhadap penggerek batang \\
$\delta$ & tingkat interaksi padi terhadap tikus \\
$\omega$ & tingkat interaksi padi terhadap wereng batang coklat
\end{tabular}

$\begin{array}{cc}\text { Satuan } & \text { Nilai } \\ \text { rumpun } & K>0 \\ \text { per waktu } & 0<r<1 \\ \text { per ekor per waktu } & 0<\alpha<1 \\ \text { per ekor per waktu } & 0<\beta<1 \\ \text { per ekor per waktu } & 0<\theta<1 \\ \text { per waktu } & 0<c<1 \\ \text { per waktu } & 0<b<1 \\ \text { per waktu } & 0<m<1 \\ \text { per rumpun per waktu } & 0<\gamma<1 \\ \text { per rumpun per waktu } & 0<\delta<1 \\ \text { per rumpun per waktu } & 0<\omega<1\end{array}$

$$
\begin{gathered}
\text { Nilai } \\
P \geq 0 \\
B \geq 0 \\
T \geq 0 \\
W \geq 0
\end{gathered}
$$




\section{Perubahan Jumlah Padi (Prey) $P$ terhadap Waktu}

Perubahan jumlah padi $P$ dipengaruhi oleh ada atau tidaknya interaksi dengan ketiga predator. Saat tidak terjadi interaksi dengan ketiga predator, pertumbuhan populasi padi mengikuti model logistik dengan daya dukung lingkungan $K$ dan tingkat pertumbuhan instrinsik sebesar $r$. Jadi populasi padi akan bertambah dengan laju $r P\left(1-\frac{P}{K}\right)$. Pengurangan jumlah padi (prey) $P$ dipengaruhi oleh: (a) banyaknya padi yang berinteraksi dengan penggerek batang dengan tingkat interaksi sebesar $\alpha$; (b) banyaknya padi yang berinteraksi dengan tikus dengan tingkat interaksi sebesar $\beta$; dan (c) banyaknya padi yang berinteraksi dengan wereng batang coklat dengan tingkat interaksi sebesar $\theta$. Dengan demikian diperoleh laju perubahan jumlah padi (prey) terhadap waktu yaitu:

$\frac{d P}{d t}=r P\left(1-\frac{P}{K}\right)-\alpha B P-\beta T P-\theta W P$.

\section{Perubahan Jumlah Penggerek Batang $B$ terhadap Waktu}

Penambahan jumlah penggerek batang $B$ dipengaruhi oleh banyaknya penggerek batang yang berinteraksi dengan padi dengan tingkat interaksi sebesar $\gamma$. Pengurangan jumlah penggerek batang $B$ dipengaruhi oleh banyaknya penggerek batang yang mengalami kematian alami dengan tingkat kematian alami sebesar $c$. Dengan demikian diperoleh laju perubahan jumlah penggerek batang terhadap waktu yaitu:

$\frac{d B}{d t}=-c B+\gamma B P$.

\section{Perubahan jumlah tikus $\boldsymbol{T}$ terhadap waktu}

Penambahan jumlah tikus $T$ dipengaruhi oleh banyaknya tikus yang berinteraksi dengan padi dengan tingkat interaksi sebesar $\delta$. Pengurangan jumlah tikus $T$ dipengaruhi oleh banyaknya tikus yang mengalami kematian alami dengan tingkat kematian alami sebesar $b$. Dengan demikian diperoleh laju perubahan jumlah tikus terhadap waktu yaitu:

$\frac{d T}{d t}=-b T+\delta T P$.

\section{Perubahan Jumlah Wereng Batang Coklat $W$ terhadap Waktu}

Penambahan jumlah wereng batang coklat $W$ dipengaruhi oleh banyaknya wereng batang coklat yang berinteraksi dengan padi dengan tingkat interaksi sebesar $\omega$. Pengurangan jumlah wereng batang coklat $W$ dipengaruhi oleh banyaknya wereng batang coklat yang mengalami kematian alami dengan tingkat kematian alami sebesar $m$. Dengan demikian diperoleh laju perubahan jumlah wereng batang coklat terhadap waktu yaitu: $\frac{d W}{d t}=-m W+\omega W P$.

Jadi, diperoleh model predator-prey antara padi, penggerek batang, tikus, dan wereng batang coklat sebagai berikut:

$$
\begin{aligned}
& \frac{d P}{d t}=r P\left(1-\frac{P}{K}\right)-\alpha B P-\beta T P-\theta W P \\
& \frac{d B}{d t}=-c B+\gamma B P \\
& \frac{d T}{d t}=-b T+\delta T P \\
& \frac{d W}{d t}=-m W+\omega W P
\end{aligned}
$$

Titik ekuilibrium sistem (1) diperoleh jika

$\frac{d P}{d t}=\frac{d B}{d t}=\frac{d T}{d t}=\frac{d W}{d t}=0$

sehingga diperoleh lima titik ekuilibrium yaitu

$E_{1}=\left(P^{*}, B^{*}, T^{*}, W^{*}\right)=(0,0,0,0)$

$E_{2}=\left(P^{*}, B^{*}, T^{*}, W^{*}\right)=(K, 0,0,0)$

$E_{3}=\left(P^{*}, B^{*}, T^{*}, W^{*}\right)=\left(\frac{c}{\gamma}, \frac{r}{\alpha}\left(1-\frac{c}{\gamma K}\right), 0,0\right)$

$E_{4}=\left(P^{*}, B^{*}, T^{*}, W^{*}\right)=\left(\frac{b}{\delta}, 0, \frac{r}{\beta}\left(1-\frac{b}{\delta K}\right), 0\right)$

$E_{5}=\left(P^{*}, B^{*}, T^{*}, W^{*}\right)=\left(\frac{m}{\omega}, 0,0, \frac{r}{\theta}\left(1-\frac{m}{\omega K}\right)\right)$.

Selanjutnya, analisis perilaku model dilakukan dengan terlebih dahulu membentuk matriks Jacobian hasil linierisasi Sistem (1) di titik ekuilibrium. Matriks Jacobian hasil linierisasi model predator-prey antara padi, penggerek batang, tikus, dan wereng batang coklat di sekitar titik ekuilibrium $E_{i}=\left(P^{*}, B^{*}, T^{*}, W^{*}\right)$ adalah

$$
J_{E_{i}}=\left[\begin{array}{cccc}
S & -\alpha P & -\beta P & -\theta P \\
\gamma B & -c+\gamma P & 0 & 0 \\
\delta T & 0 & -b+\delta P & 0 \\
\omega W & 0 & 0 & -m+\omega P
\end{array}\right] .
$$

dengan $S=r-\frac{2 r}{K} P-\alpha B-\beta T-\theta W$. 
Analisis perilaku model hanya dilakukan pada titik ekuilibrium $E_{3}, E_{4}$, dan $E_{5}$ karena pada titik ekuilibrium $E_{1}$ dan $E_{2}$, jumlah penggerek batang, tikus, dan wereng batang coklat bernilai nol. Hasil linierisasi Sistem (1) di sekitar titik ekuilibrium $E_{i}$ adalah:

$$
\left(\begin{array}{c}
\frac{d P}{d t} \\
\frac{d B}{d t} \\
\frac{d T}{d t} \\
\frac{d W}{d t}
\end{array}\right)=J_{E_{i}}\left(\begin{array}{c}
P \\
B \\
T \\
W
\end{array}\right)
$$

Analisis Perilaku Model di Titik Ekuilibrium $E_{3}=\left(\frac{c}{\gamma}, \frac{r}{\alpha}\left(1-\frac{c}{\gamma K}\right), 0,0\right)$

Jika titik ekuilibrium $E_{3}$ disubstituskan ke Persamaan (2), maka diperoleh matriks $J_{E_{3}}$ yaitu matriks Jacobian di sekitar titik ekuilibrium $E_{3}$ sebagai berikut.

$$
J_{E_{3}}=\left[\begin{array}{cccc}
-\frac{r c}{\gamma K} & \frac{-\alpha c}{\gamma} & \frac{-\beta c}{\gamma} & \frac{-\theta c}{\gamma} \\
\frac{\gamma r}{\alpha}-\frac{r c}{\alpha K} & 0 & 0 & 0 \\
0 & 0 & -b+\frac{\delta c}{\gamma} & 0 \\
0 & 0 & 0 & -m+\frac{\omega c}{\gamma}
\end{array}\right] .
$$

Persamaan karakteristik untuk $J_{E_{3}}$ adalah

$$
\begin{aligned}
& \left|J_{E_{3}}-\lambda I\right|=0 \\
& \Leftrightarrow\left[\left(-m+\frac{\omega c}{\gamma}\right)-\lambda\right]\left[\left(-b+\frac{\delta c}{\gamma}\right)-\lambda\right] \\
& \quad\left[\lambda\left(\frac{r c}{\gamma K}+\lambda\right)+\frac{\alpha c}{\gamma}\left(\frac{\gamma r}{\alpha}-\frac{r c}{\alpha K}\right)\right]=0 .
\end{aligned}
$$

Berdasarkan Persamaan karakteristik (3), diperoleh nilai eigen pertama dan kedua yaitu

$$
\lambda_{1}=-m+\frac{\omega c}{\gamma}, \lambda_{2}=-b+\frac{\delta c}{\gamma} \text {. }
$$

Nilai eigen $\lambda_{1}<0$ jika $m>\frac{\omega c}{\gamma}$ dan nilai eigen $\lambda_{2}<0$ jika $b>\frac{\delta c}{\gamma}$. Dengan demikian, bagian riil nilai eigen pertama dan kedua, yaitu $\operatorname{Re}\left(\lambda_{1}\right)$ dan $\operatorname{Re}\left(\lambda_{2}\right)$ bernilai negatif jika $m>\frac{\omega c}{\gamma}$ dan $b>\frac{\delta c}{\gamma}$.

Penentuan bagian riil nilai eigen ketiga dan keempat, yaitu $\operatorname{Re}\left(\lambda_{3}\right)$ dan $\operatorname{Re}\left(\lambda_{4}\right)$ diperoleh dari persamaan berikut:

$$
\begin{aligned}
& \lambda\left(\frac{r c}{\gamma K}+\lambda\right)+\frac{\alpha c}{\gamma}\left(\frac{\gamma r}{\alpha}-\frac{r c}{\alpha K}\right)=0 \\
& \Leftrightarrow \lambda^{2}+\frac{r c}{\gamma K} \lambda+c r\left(1-\frac{c}{\gamma K}\right)=0
\end{aligned}
$$

Berdasarkan Persamaan (4) diperoleh $a_{0}=1$, $a_{1}=\frac{c r}{\gamma K}$, dan $a_{2}=c r\left(1-\frac{c}{\gamma K}\right)$. Diperhatikan bahwa $\frac{a_{1}}{a_{0}}=\frac{c r}{\gamma K}>0$. Oleh karena $K>0$, $0<c<1$, dan $0<\gamma<1$, maka $0<\frac{c}{\gamma K}<1$ sehingga $1-\frac{c}{\gamma K}>0$, akibatnya $\frac{a_{2}}{a_{0}}>0$.

Selanjutnya, diperhatikan matriks Hurwitz $H=\left[\begin{array}{ll}a_{1} & a_{0} \\ 0 & a_{2}\end{array}\right]$

sehingga diperoleh determinan matriks Hurwitz

$$
\begin{aligned}
& \Delta_{1}=\left|a_{1}\right|=\frac{c r}{\gamma K}>0 \\
& \Delta_{2}=\left|\begin{array}{ll}
a_{1} & a_{0} \\
0 & a_{2}
\end{array}\right|=\frac{c^{2} r^{2}}{\gamma K}\left(1-\frac{c}{\gamma K}\right)>0 .
\end{aligned}
$$

Determinan matriks Hurwitz $\Delta_{1}$ dan $\Delta_{2}$ bernilai positif. Jadi, semua bagian riil nilai eigen dari Persamaan (4), yaitu $\operatorname{Re}\left(\lambda_{3}\right)$ dan $\operatorname{Re}\left(\lambda_{4}\right)$ bernilai negatif. Dengan demikian, titik 
ekuilibrium $E_{3}$ adalah titik ekuilibrium hiperbolik jika $m>\frac{\omega c}{\gamma}$ dan $b>\frac{\delta c}{\gamma}$.

Kestabilan titik ekuilibrium $E_{3}$ bergantung pada tanda dari keempat nilai eigen persamaan karakteristik (3) sehingga diperoleh kestabilan titik ekuilibrium $E_{3}$ hasil linierisasi Sistem (1) adalah stabil asimtotik lokal jika $m>\frac{\omega c}{\gamma}$ dan $b>\frac{\delta c}{\gamma}$. Jadi, titik ekuilibrium $E_{3}$ juga akan stabil asimtotik lokal jika $m>\frac{\omega c}{\gamma}$ dan $b>\frac{\delta c}{\gamma}$.

Analisis Perilaku Model di Titik Ekuilibrium $E_{4}=\left(\frac{b}{\delta}, 0, \frac{r}{\beta}\left(1-\frac{b}{\delta K}\right), 0\right)$

Jika titik ekuilibrium $E_{4}$ disubstituskan ke Persamaan (2), maka diperoleh matriks $J_{E_{4}}$ yaitu matriks Jacobian di sekitar titik ekuilibrium $E_{4}$ sebagai berikut.

$$
J_{E_{4}}=\left[\begin{array}{cccc}
-\frac{r b}{\delta K} & \frac{-\alpha b}{\delta} & \frac{-\beta b}{\delta} & \frac{-\theta b}{\delta} \\
0 & -c+\frac{\gamma b}{\delta} & 0 & 0 \\
\frac{\delta r}{\beta}\left(1-\frac{b}{\delta K}\right) & 0 & 0 & 0 \\
0 & 0 & 0 & -m+\frac{\omega b}{\delta}
\end{array}\right] \text {. }
$$

Persamaan karakteristik untuk $J_{E_{4}}$ adalah

$$
\begin{aligned}
& \left|J_{E_{4}}-\lambda I\right|=0 \\
& \Leftrightarrow\left[\left(-m+\frac{\omega b}{\delta}\right)-\lambda\right]\left[-c+\frac{\gamma b}{\delta}-\lambda\right] \\
& {\left[\lambda^{2}+\frac{r b}{\delta K} \lambda+b r\left(1-\frac{b}{\delta K}\right)\right]=0}
\end{aligned}
$$

Berdasarkan Persamaan karakteristik (5), diperoleh nilai eigen pertama dan kedua yaitu:

$$
\lambda_{1}=-m+\frac{\omega b}{\delta}, \lambda_{2}=-c+\frac{\gamma b}{\delta} .
$$

Nilai eigen $\lambda_{1}<0$ jika $m>\frac{\omega b}{\delta}$ dan nilai eigen $\lambda_{2}<0$ jika $c>\frac{\gamma b}{\delta}$. Dengan demikian, bagian riil nilai eigen pertama dan kedua, yaitu $\operatorname{Re}\left(\lambda_{1}\right)$ dan $\operatorname{Re}\left(\lambda_{2}\right)$ bernilai negatif jika $m>\frac{\omega b}{\delta}$ dan $c>\frac{\gamma b}{\delta}$.

Penentuan bagian riil nilai eigen ketiga dan keempat, yaitu $\operatorname{Re}\left(\lambda_{3}\right)$ dan $\operatorname{Re}\left(\lambda_{4}\right)$ diperoleh dari persamaan berikut:

$$
\lambda^{2}+\frac{r b}{\delta K} \lambda+b r\left(1-\frac{b}{\delta K}\right)=0
$$

Berdasarkan Persamaan (6) diperoleh $a_{0}=1$, $a_{1}=\frac{r b}{\delta K}$, dan $a_{2}=b r\left(1-\frac{b}{\delta K}\right)$. Diperhatikan bahwa $\frac{a_{1}}{a_{0}}=\frac{r b}{\delta K}>0$. Oleh karena $K>0$, $0<b<1$, dan $0<\delta<1$, maka $0<\frac{b}{\delta K}<1$ sehingga $1-\frac{b}{\delta K}>0$, akibatnya $\frac{a_{2}}{a_{0}}>0$.

Selanjutnya, diperhatikan matriks Hurwitz $H=\left[\begin{array}{ll}a_{1} & a_{0} \\ 0 & a_{2}\end{array}\right]$

sehingga diperoleh determinan matriks Hurwitz

$$
\begin{aligned}
& \Delta_{1}=\left|a_{1}\right|=\frac{r b}{\delta K}>0 \\
& \Delta_{2}=\left|\begin{array}{ll}
a_{1} & a_{0} \\
0 & a_{2}
\end{array}\right|=\frac{r^{2} b^{2}}{\gamma K}\left(1-\frac{b}{\delta K}\right)>0 .
\end{aligned}
$$

Determinan matriks Hurwitz $\Delta_{1}$ dan $\Delta_{2}$ bernilai positif. Jadi, semua bagian riil nilai eigen dari Persamaan (6), yaitu $\operatorname{Re}\left(\lambda_{3}\right)$ dan $\operatorname{Re}\left(\lambda_{4}\right)$ bernilai negatif. Dengan demikian, titik ekuilibrium $E_{4}$ adalah titik ekuilibrium hiperbolik jika $m>\frac{\omega b}{\delta}$ dan $c>\frac{\gamma b}{\delta}$. 
Kestabilan titik ekuilibrium $E_{4}$ bergantung pada tanda dari keempat nilai eigen Persamaan karakteristik (5) sehingga diperoleh kestabilan titik ekuilibrium $E_{4}$ hasil linierisasi Sistem (1) adalah stabil asimtotik lokal jika $m>\frac{\omega b}{\delta}$ dan $c>\frac{\gamma b}{\delta}$. Jadi, titik ekuilibrium $E_{4}$ juga akan stabil asimtotik lokal jika $m>\frac{\omega b}{\delta}$ dan $c>\frac{\gamma b}{\delta}$.

Analisis Perilaku Model di Titik Ekuilibrium $E_{5}=\left(\frac{m}{\omega}, 0,0, \frac{r}{\theta}\left(1-\frac{m}{\omega K}\right)\right)$

Jika titik ekuilibrium $E_{5}$ disubstituskan ke Persamaan (2), maka diperoleh matriks $J_{E_{5}}$ yaitu matriks Jacobian di sekitar titik ekuilibrium $E_{5}$ sebagai berikut.

$$
J_{E_{5}}=\left[\begin{array}{cccc}
-\frac{r m}{\omega K} & -\alpha \frac{m}{\omega} & -\beta \frac{m}{\omega} & -\theta \frac{m}{\omega} \\
0 & -c+\gamma \frac{m}{\omega} & 0 & 0 \\
0 & 0 & -b+\delta \frac{m}{\omega} & 0 \\
\frac{\omega r}{\theta}\left(1-\frac{m}{\omega K}\right) & 0 & 0 & 0
\end{array}\right] .
$$

Persamaan karakteristik untuk $J_{E_{5}}$ adalah

$$
\begin{aligned}
& \left|J_{E_{5}}-\lambda I\right|=0 \\
& \Leftrightarrow\left[\left(-c+\gamma \frac{m}{\omega}\right)-\lambda\right]\left[\left(-b+\delta \frac{m}{\omega}\right)-\lambda\right] \\
& {\left[\lambda^{2}+\frac{r m}{\omega K} \lambda+r m\left(1-\frac{m}{\omega K}\right)\right]=0 .}
\end{aligned}
$$

Berdasarkan Persamaan karakteristik (7), diperoleh nilai eigen pertama dan kedua yaitu

$$
\lambda_{1}=-c+\gamma \frac{m}{\omega}, \lambda_{2}=-b+\delta \frac{m}{\omega} .
$$

Nilai eigen $\lambda_{1}<0$ jika $c>\frac{\gamma m}{\omega}$ dan nilai eigen $\lambda_{2}<0$ jika $b>\frac{\delta m}{\omega}$. Dengan demikian, bagian riil nilai eigen pertama dan kedua, yaitu $\operatorname{Re}\left(\lambda_{1}\right)$ dan $\operatorname{Re}\left(\lambda_{2}\right)$ bernilai negatif jika $c>\frac{\gamma m}{\omega}$ dan $b>\frac{\delta m}{\omega}$.

Penentuan bagian riil nilai eigen ketiga dan keempat, yaitu $\operatorname{Re}\left(\lambda_{3}\right)$ dan $\operatorname{Re}\left(\lambda_{4}\right)$ diperoleh dari persamaan berikut:

$$
\lambda^{2}+\frac{r m}{\omega K} \lambda+r m\left(1-\frac{m}{\omega K}\right)
$$

Berdasarkan Persamaan (8) diperoleh $a_{0}=1$, $a_{1}=\frac{r m}{\omega K}$, dan $a_{2}=r m\left(1-\frac{m}{\omega K}\right)$. Diperhatikan bahwa $\frac{a_{1}}{a_{0}}=\frac{r m}{\omega K}>0$. Oleh karena $K>0$, $0<m<1$, dan $0<\omega<1$, maka $0<\frac{m}{\omega K}<1$ sehingga $1-\frac{m}{\omega K}>0$, akibatnya $\frac{a_{2}}{a_{0}}>0$.

Selanjutnya, diperhatikan matriks Hurwitz $H=\left[\begin{array}{cc}a_{1} & a_{0} \\ 0 & a_{2}\end{array}\right]$

sehingga diperoleh determinan matriks Hurwitz

$$
\begin{aligned}
& \Delta_{1}=\left|a_{1}\right|=\frac{r m}{\omega K}>0 \\
& \Delta_{2}=\left|\begin{array}{cc}
a_{1} & a_{0} \\
0 & a_{2}
\end{array}\right|=\frac{r^{2} m^{2}}{\omega K}\left(1-\frac{m}{\omega K}\right)>0 .
\end{aligned}
$$

Determinan matriks Hurwitz $\Delta_{1}$ dan $\Delta_{2}$ bernilai positif. Jadi, semua bagian riil nilai eigen dari Persamaan (8), yaitu $\operatorname{Re}\left(\lambda_{3}\right)$ dan $\operatorname{Re}\left(\lambda_{4}\right)$ bernilai negatif. Dengan demikian, titik ekuilibrium $E_{5}$ adalah titik ekuilibrium hiperbolik jika $c>\frac{\gamma m}{\omega}$ dan $b>\frac{\delta m}{\omega}$.

Kestabilan titik ekuilibrium $E_{5}$ bergantung pada tanda dari keempat nilai eigen Persamaan karakteristik (7) sehingga diperoleh kestabilan titik ekuilibrium $E_{5}$ hasil linierisasi Sistem (1) adalah stabil asimtotik lokal jika $c>\frac{\gamma m}{\omega}$ dan $b>\frac{\delta m}{\omega}$. Jadi, titik ekuilibrium $E_{5}$ 
juga akan stabil asimtotik lokal jika $c>\frac{\gamma m}{\omega}$ dan $b>\frac{\delta m}{\omega}$.

Selanjutnya simulasi model dilakukan pada titik ekuilibrium $E_{3}, E_{4}$, dan $E_{5}$. Beberapa nilai variabel dan parameter diperoleh dengan perhitungan berikut.

Daya Dukung Lingkungan untuk Padi (Prey)

Luas baku sawah di Kabupaten Karawang pada tahun 2013 adalah 98.346 ha (DPKPP Kabupaten Karawang, 2013). Jumlah rumpun padi per hektar adalah 170.000 rumpun/ha (Firmana, Nurmalina, \& Rifin, 2017). Oleh karena itu, daya dukung lingkungan untuk padi (prey) adalah

$$
\begin{aligned}
K & =98.346 \text { ha } \times 170.000 \text { rumpun } / \text { ha } \\
& =16.718 .820 .000 \text { rumpun } .
\end{aligned}
$$

Tingkat Pertumbuhan Intrinsik Padi (Prey)

Luas tanam padi sawah di Kabupaten Karawang pada tahun 2012 adalah 94.983 ha dan tahun 2013 adalah 97.598 ha (DPKPP Kabupaten Karawang, 2013). Jadi, tingkat pertumbuhan intrinsik padi (prey) adalah

$$
\begin{aligned}
r & =\frac{(97.598-94.983) \mathrm{ha}}{97.598 \mathrm{ha}} \\
& =\frac{2.615}{97.598} \\
& =0,0268 .
\end{aligned}
$$

Jumlah Subpopulasi Awal Padi (Prey)

Luas tanam padi sawah di Kabupaten Karawang pada tahun 2013 adalah 97.598 ha (DPKPP Kabupaten Karawang, 2013). Jumlah rumpun padi per hektar adalah 170.000 rumpun/ha (Firmana, Nurmalina, \& Rifin, 2017). Jadi, jumlah subpopulasi awal padi (prey) P adalah

$$
\begin{aligned}
P(0) & =97.598 \text { ha } \times 170.000 \mathrm{rumpun} / \mathrm{ha} \\
& =16.591 .660 .000 \mathrm{rumpun} .
\end{aligned}
$$

Jumlah Subpopulasi Awal Penggerek Batang

Luas serangan penggerek batang di Kabupaten Karawang pada tahun 2013 adalah 9.894 ha (DPKPP Kabupaten Karawang, 2013). Jumlah rumpun padi per hektar adalah 170.000 rumpun/ha (Firmana, Nurmalina, \& Rifin, 2017).
Rata-rata jumlah penggerek batang padi adalah 0,46 ekor/rumpun (Damayanti, Mudjiono, \& Karindah, 2015). Jadi, jumlah subpopulasi awal penggerek batang $B$ adalah

$$
\begin{aligned}
B(0)= & 0,46 \text { ekor/rumpun } \times 9.894 \text { ha } \times \\
& 170.000 \text { rumpun } / \text { ha } \\
= & 773.710 .800 \text { ekor. }
\end{aligned}
$$

Jumlah subpopulasi awal tikus.

Luas serangan tikus di Kabupaten Karawang pada tahun 2013 adalah 3.633 ha (DPKPP Kabupaten Karawang, 2013). Jumlah rumpun padi per hektar adalah 170.000 rumpun/ha (Firmana, Nurmalina, \& Rifin, 2017). Menurut penelitian Sudarmaji dan Anggara yang dilakukan pada 50 rumpun padi diperoleh tangkapan tikus sebanyak 70 ekor, sehingga rata-rata jumlah tikus adalah:

\section{$(70 / 50)$ ekor/rumpun = 1,4 ekor/rumpun}

(Sudarmaji \& Anggara, 2006) Jadi, jumlah subpopulasi awal tikus $T$ adalah

$$
\begin{aligned}
T(0)= & 1,4 \text { ekor/rumpun } \times 3.633 \text { ha } \times \\
& 170.000 \text { rumpun } / \text { ha } \\
= & 864.654 .000 \text { ekor. }
\end{aligned}
$$

Jumlah Subpopulasi Awal Wereng Batang Coklat

Luas serangan wereng batang coklat di Kabupaten Karawang pada tahun 2013 adalah 627 ha (DPKPP Kabupaten Karawang, 2013). Jumlah rumpun padi per hektar adalah 170.000 rumpun/ha (Firmana, Nurmalina, \& Rifin, 2017). Rata-rata jumlah wereng batang coklat adalah 0,02 ekor/rumpun (Baehaki \& Widiarta, 2009). Jadi, jumlah subpopulasi awal wereng batang coklat $W$ adalah

$$
\begin{aligned}
W(0)= & 0,02 \text { ekor/rumpun } \times 627 \text { ha } \times \\
& 170.000 \text { rumpun } / \text { ha } \\
= & 2.131 .800 \text { ekor. }
\end{aligned}
$$

Tingkat Kematian Alami Tikus

Tingkat kematian tikus adalah 29,63\% sehingga $b=0,2963$ (Ridatiningsih, 2017).

Tingkat Kematian Alami Wereng Batang Coklat

Tingkat kematian wereng batang coklat adalah 90\% sehingga $m=0,9$ (Laba, 2001).

Nilai parameter $K$ serta nilai-nilai variabel $\mathrm{P}(0), B(0), T(0)$, dan $W(0)$ agar tidak terlalu besar, 
diambil pendekatannya setelah dibagi dengan 1.000.000 sehingga menjadi

$$
\begin{aligned}
& K=16.720 \text { rumpun } \\
& P(0)=16.600 \text { rumpun } \\
& B(0)=774 \text { ekor } \\
& T(0)=865 \text { ekor } \\
& W(0)=2 \text { ekor. }
\end{aligned}
$$

Selanjutnya, nilai-nilai parameter berikut ditentukan tanpa perhitungan.

Tabel 3. Daftar Nilai Parameter untuk Simulasi

\begin{tabular}{clcc} 
Simbol & \multicolumn{1}{c}{ Definisi } & Satuan & Nilai \\
$\alpha$ & $\begin{array}{l}\text { tingkat interaksi } \\
\text { penggerek batang } \\
\text { per ekor }\end{array}$ & $\begin{array}{c}\text { per waktu } \\
\text { terhadap padi }\end{array}$ & \\
$\beta$ & $\begin{array}{l}\text { tingkat interaksi } \\
\text { tikus terhadap padi }\end{array}$ & $\begin{array}{c}\text { per ekor } \\
\text { per waktu }\end{array}$ & 0,001 \\
$\theta$ & $\begin{array}{l}\text { tingkat interaksi } \\
\text { per ekor }\end{array}$ & 0,001 \\
& $\begin{array}{l}\text { wereng batang } \\
\text { coklat terhadap } \\
\text { padi }\end{array}$ & per waktu & \\
$\boldsymbol{m}$ & $\begin{array}{l}\text { tingkat kematian } \\
\text { alami wereng } \\
\text { batang coklat } \\
\text { tingkat interaksi } \\
\text { padi terhadap tikus }\end{array}$ & per waktu & 0,9 \\
& & per & 0,001 \\
& & per waktu &
\end{tabular}

Nilai-nilai parameter pada Tabel 3 digunakan pada simulasi titik ekuilibrium $E_{3}, E_{4}$, dan $E_{5}$.

\section{Simulasi di Titik Ekuilibrium $E_{3}$}

Pada simulasi di titik ekuilibrium $E_{3}$, dipilih nilai parameter $\gamma=0,002$ dan $\omega=0,002$ sehingga $\frac{\omega c}{\gamma}=0,3$ dan $\frac{\delta c}{\gamma}=0,15$. Ini berarti, $m>\frac{\omega c}{\gamma}$ dan $b>\frac{\delta c}{\gamma}$ sehingga diperoleh titik ekuilibrium $E_{3}$ yaitu $E_{3}=(150 ; 26,56 ; 0 ; 0)$. Berikut ini adalah grafik hasil simulasi di titik ekuilibrium $E_{3}$ dengan menggunakan sofware Maple 13.

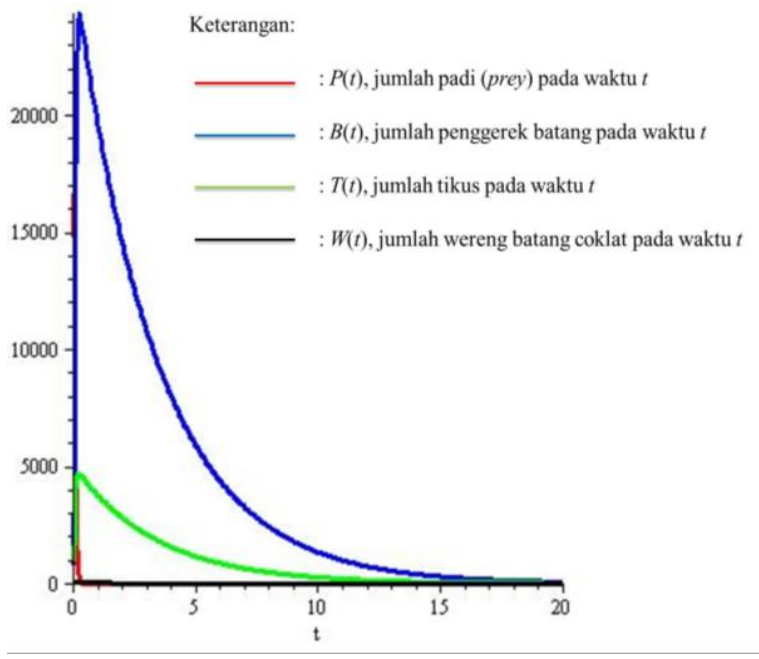

Gambar 1. Grafik $P, B, T$, dan $W$ di Titik Ekuilibrium $E_{3}$

Berdasarkan Gambar 1, jumlah padi (prey) $P$ akan menuju ke 150 rumpun, jumlah penggerek batang $B$ akan menuju ke 26,56 ekor, serta jumlah tikus $T$ dan jumlah wereng batang coklat $W$ akan hilang dari populasi.

Diperhatikan kembali bahwa sebelumnya, jumlah setiap subpopulasi awal $P, B, T$, dan $W$ dibagi dengan 1.000.000, sehingga untuk jangka waktu tertentu, nilai yang sebenarnya untuk jumlah padi (prey) $P$ akan menuju ke 150.000 .000 rumpun dan jumlah penggerek batang $B$ akan menuju ke 26.560.000 ekor. Serangan tikus dan wereng batang coklat tidak ada lagi, artinya faktor-faktor yang berpengaruh agar serangan tikus dan wereng batang coklat menghilang dari populasi adalah tingkat kematian alami ketiga hama $(c, b, \operatorname{dan} m)$ serta tingkat interaksi padi terhadap ketiga hama tersebut $(\gamma, \delta$, dan $\omega)$.

\section{Simulasi di Titik Ekuilibrium $E_{4}$}

Pada simulasi di titik ekuilibrium $E_{4}$, dipilih nilai parameter $\gamma=0,001$ dan $\omega=0,002$ sehingga $\frac{\omega b}{\delta}=0,59$ dan $\frac{\gamma b}{\delta}=0,29$. Ini berarti, $m>\frac{\omega b}{\delta}$ dan $c>\frac{\gamma b}{\delta}$ sehingga diperoleh titik ekuilibrium $E_{4}=(296,3 ; 0 ; 26,32 ; 0)$. Berikut ini adalah grafik hasil simulasi di titik ekuilibrium $E_{4}$ dengan menggunakan sofware Maple 13. 
Pythagoras, 13 (1), 2018 - 61

Tesa Nur Padilah, Betha Nurina Sari, H. Hannie

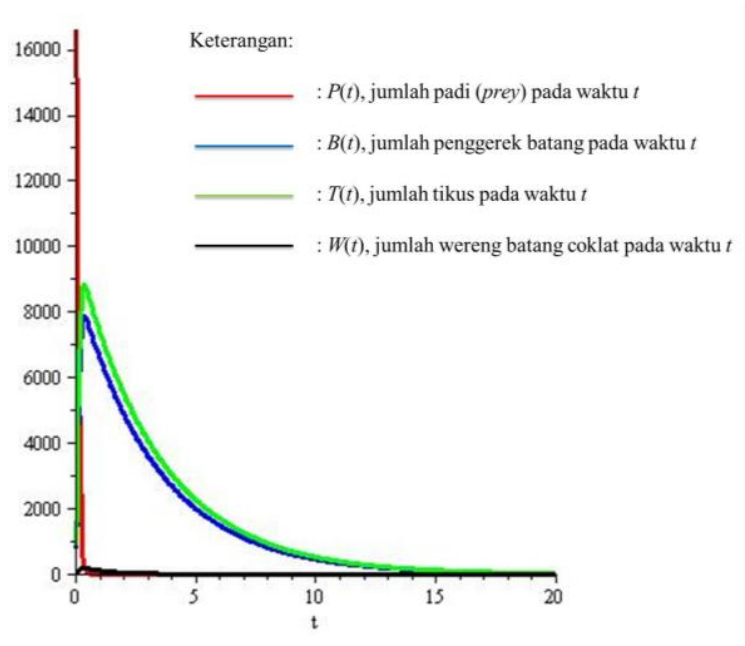

Gambar 2. Grafik $P, B, T$, dan $W$ di Titik Ekuilibrium $E_{4}$

Berdasarkan Gambar 2, jumlah padi (prey) $P$ akan menuju ke 296,3 rumpun, jumlah tikus $T$ akan menuju ke 26,32 ekor, serta jumlah penggerek batang $B$ dan jumlah wereng batang coklat $W$ akan hilang dari populasi.

Diperhatikan kembali bahwa sebelumnya, jumlah setiap subpopulasi awal $P, B, T$, dan $W$ dibagi dengan 1.000.000, sehingga nilai yang sebenarnya untuk jumlah padi (prey) $P$ akan menuju ke 296.300.000 rumpun dan jumlah tikus $T$ akan menuju ke 26.320.000 ekor. Serangan penggerek batang dan wereng batang coklat tidak ada lagi, artinya faktor-faktor yang berpengaruh agar serangan penggerek batang dan wereng batang coklat menghilang dari populasi adalah tingkat kematian alami ketiga hama $(c, b$, dan $m)$ serta tingkat interaksi padi terhadap ketiga hama tersebut $(\gamma, \delta$, dan $\omega)$.

\section{Simulasi di Titik Ekuilibrium $E_{5}$}

Pada simulasi di titik ekuilibrium $E_{5}$, dipilih nilai parameter $\gamma=0,002$ dan $\omega=0,007$ sehingga $\frac{\gamma m}{\omega}=0,26$ dan $\frac{\delta m}{\omega}=0,13$. Ini berarti, $c>\frac{\gamma m}{\omega}$ dan $b>\frac{\delta m}{\omega}$ sehingga diperoleh titik $E_{5}$ yaitu $E_{5}=(128,57 ; 0 ; 0 ; 26,59)$. Berikut ini adalah grafik hasil simulasi di titik ekuilibrium $E_{5}$ dengan menggunakan sofware Maple 13.

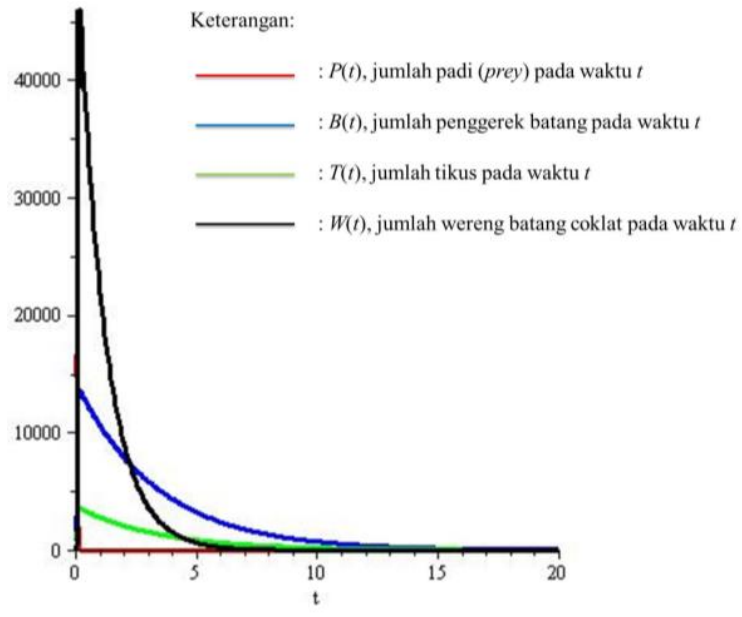

Gambar 3. Grafik $P, B, T$, dan $W$ di Titik Ekuilibrium $E_{5}$

Berdasarkan Gambar 3, jumlah padi (prey) $P$ akan menuju ke 128,57 rumpun, jumlah wereng batang coklat $W$ akan menuju ke 26,59 ekor, serta jumlah penggerek batang $B$ dan jumlah tikus $T$ akan hilang dari populasi.

Diperhatikan kembali bahwa sebelumnya, jumlah setiap subpopulasi awal $P, B, T$, dan $W$ dibagi dengan 1.000.000, sehingga nilai yang sebenarnya untuk jumlah padi (prey) $P$ akan menuju ke 128.570.000 rumpun dan jumlah wereng batang coklat $W$ akan menuju ke 26.590.000 ekor. Serangan penggerek batang dan tikus tidak ada lagi, artinya faktor-faktor yang berpengaruh agar serangan penggerek batang dan tikus menghilang dari populasi adalah tingkat kematian alami ketiga hama $(c, b$, dan $m)$ serta tingkat interaksi padi terhadap ketiga hama tersebut $(\gamma, \delta$, dan $\omega)$.

\section{SIMPULAN}

Berdasarkan hasil dan pembahasan, diperoleh kesimpulan berikut: (1) model predatorprey antara tanaman padi, hama penggerek batang, tikus, dan wereng batang coklat berupa sistem persamaan diferensial nonlinier dengan empat variabel; (2) analisis perilaku model predator-prey antara padi, hama penggerek batang, tikus, dan wereng batang coklat di sekitar titik ekuilibrium $E_{3}, E_{4}$, dan $E_{5}$ bersifat stabil asimtotik lokal, Ini berarti untuk jangka waktu tertentu, perubahan jumlah padi, penggerek batang, tikus, dan wereng batang coklat akan menuju ke titik ekuilibrium; dan (3) hasil simulasi model dengan menggunakan software Maple 13 sesuai dengan analisis perilaku model, dan faktor-faktor yang berpengaruh agar populasi hama penggerek 
batang, tikus, dan wereng batang coklat dapat menurun bahkan hilang dari populasi yaitu tingkat kematian alami serta tingkat interaksi padi terhadap ketiga hama tersebut.

Berdasarkan hasil penelitian tersebut, disarankan beberapa hal sebagai berikut: (1) untuk penelitian selanjutnya perlu dilakukan penelitian yang menyelidiki model matematis predatorprey tanaman padi dan OPT menggunakan organisme yang lebih banyak lagi (lebih dari 3 spesies); dan (2) disarankan agar peneliti lain melakukan analisis predator-prey pada objek atau konteks yang berbeda, sehingga aplikasi dari model predator-prey semakin luas.

\section{DAFTAR PUSTAKA}

Baehaki, S. E., \& Widiarta, I. N. (2009). Hama wereng dan cara pengendaliannya pada tanaman padi. Jakarta: Balai Besar Penelitian Tanaman Padi.

Damayanti, E., Mudjiono, G., \& Karindah, S. (2015). Perkembangan populasi larva penggerek batang dan musuh alaminya pada tanaman padi (Oryza Sativa L.) PHT. Jurnal Hama dan Penyakit Tumbuhan, 3(4), 18-24.

DPKPP Kabupaten Karawang. (2013). Laporan tahunan DPKPP Kabupaten Karawang tahun 2013. Karawang: Dinas Pertanian Kehutanan Perkebunan dan Peternakan Kabupaten Karawang.

DPKPP Kabupaten Karawang. (2014). Laporan tahunan DPKPP Kabupaten Karawang tahun 2014. Karawang: Dinas Pertanian Kehutanan Perkebunan dan Peternakan Kabupaten Karawang.

Edwards, C. H., \& Penney, D. E. (2008). Elementary differential equations (4th ed.). Prentice-Hall, NJ: Pearson Education.

Firmana, F., Nurmalina, R., \& Rifin, A. (2017). efisiensi teknis usahatani padi di kabupaten karawang dengan pendekatan data envelopment analysis (DEA). Forum Agribisnis, 6(2). Retrieved from http://journal.ipb.ac.id/ index.php/fagb/article/view/17255
Haberman, R. (1998). Mathematical Models: Mechanical Vibrations, Population, Dynamics, and Traffic Flow. Philadelphia, PA: Society for Industrial and Applied Mathematics.

Korobeinikov, A., \& Wake, G. C. (1999). Global properties of the three-dimensional predator-prey lotka-volterra systems. Journal of Applied Mathematics \& Decision Sciences, 3(2), 155-162.

Laba, I. W. (2001). Keanekaragaman hayati artropoda dan peranan musuh alami hama utama padi pada ekosistem sawah. Makalah Falsafah Sains (PPs IPB 702), 117.

Machowski, J., Bialek, J. W., \& Bumby, J. R. (2011). Power system dynamics: Stability and contol (4th ed.). New York, NY: John Wiley \& Sons.I

Makarim, A. K., \& Suhartatik, E. (2009). Morfologi dan fisiologi tanaman padi. Publikasi Balai Besar Penelitian Tanaman Padi, 295-329.

Nugroho, D. A., \& Reorita, R. (2013). Model Predator-Prey dengan Dua Predator. Jurnal Ilmiah Matematika dan Pendidikan Matematika, 5(1), 43-51.

Olsder, G. J., Woude, J. W. van der, Maks, J. G., \& Jeltsema, D. (2011). Mathematical Systems Theory (4th ed.). Dutch, Netherlands: VSSD.

Ridatiningsih, R. (2017). Keefektifan umpan beracun cair dalam mengendalikan tikus hama. Skripsi sarjana tidak diterbitkan. Bogor: Institut Pertanian Bogor.

Sudarmaji, S., \& Anggara, A. W. (2006). Pengendalian tikus sawah dengan sistem bubu perangkap di ekosistem sawah irigasi. Penelitian Pertanian Tanaman Pangan, 25(1), 57-65.

Wijayanti, P., \& Kharis, M. (2015). Analisis model predator-prey dua spesies dengan fungsi respon Holling tipe III. UNNES Journal of Mathematics, 4(1), 38-46. 